\title{
Food crisis escalates in Africa's Sahel region
}

Published at www.cmaj.ca on July 16

$\mathrm{P}$ leas for humanitarian assistance to help the 10 million people at risk of acute hunger in Africa's Sahel region are gaining urgency as international aid agencies struggle to keep pace with what they're calling one of the worst food crises in years.

Ten leading aid agencies - including CARE International, Oxfam, World Vision and Save the Children - have recently joined organizations such as Médecins Sans Frontières (MSF) in calling for a speedier deployment of assistance to meet the needs of the most vulnerable populations in Niger, Chad, Mali, Mauritania, parts of Burkina Faso and the extreme north of Nigeria.

Niger, the world's least-developed nation, has been hit hardest, with 7.1 million people in need of humanitarian aid - almost half its population. Nearly $17 \%$ of Nigerian children under age five suffer from acute malnutrition, placing them at risk of permanent damage or death if not treated quickly. According to recent UNICEF estimates, 378000 cases of severe acute malnutrition and 1.2 million cases of moderate acute malnutrition among children under age five will be registered in 2010, if urgent action is not taken.

In neighbouring Chad, some two million people have been affected by food shortages, with over $60 \%$ of the population at risk of going hungry, according to the recent United Nations' World Food Programme's Emergency Food Security Assessment (http://documents.wfp.org/stellent/grou ps/public/documents/communications /wfp221483.pdf). Malnutrition has spread to between 19\% and $29 \%$ of all children under five, "well above emergency thresholds" according to the report. Rates of swelling limbs, infections, and other signs of child malnourishment are on the rise at health centres in six regions. In the Hadjer Lamis region alone, some 5000 children are in urgent need of nutritional assistance.

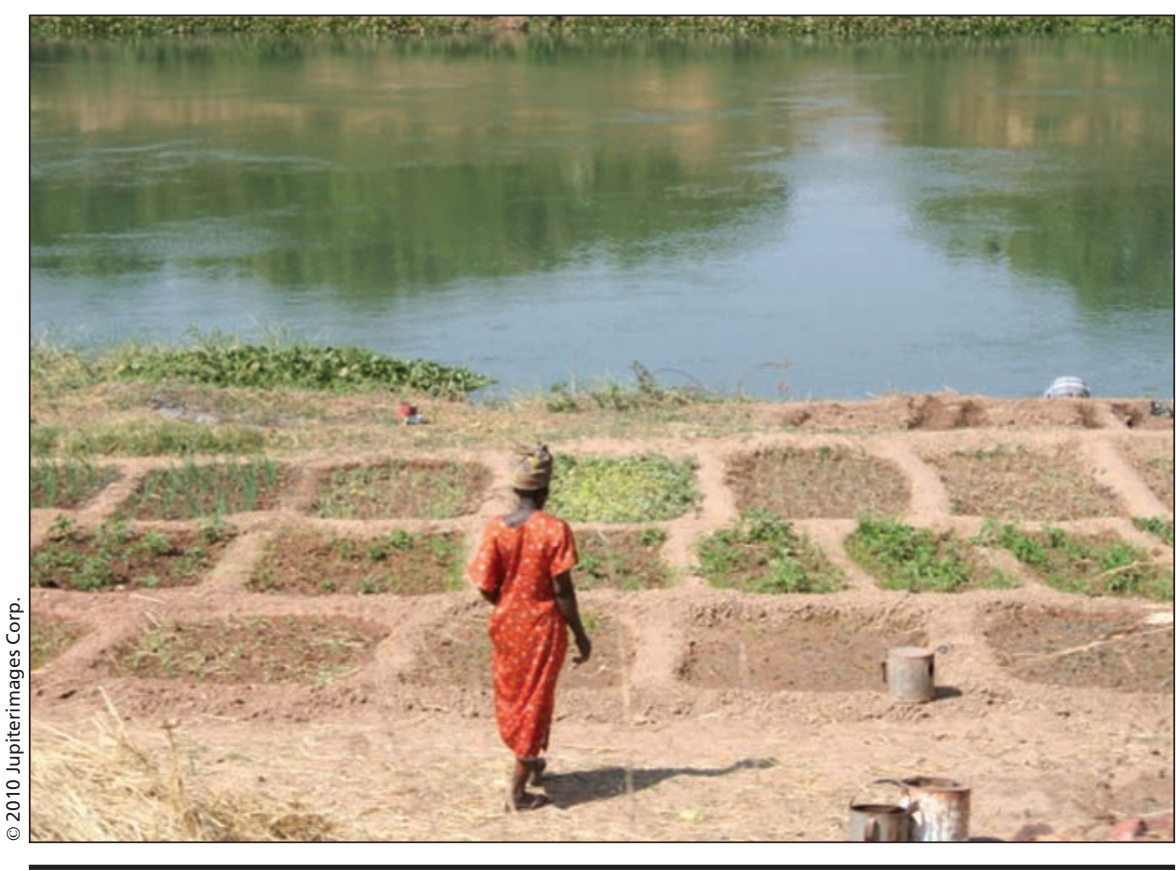

Millions of people in Africa's Sahel belt face malnutrition, as poor harvests, drought and pest infestations have led many to exhaust emergency food stocks.

"Children are the first affected and the worst affected by malnutrition because they have fewer coping mechanisms. They're in direct danger of dying, both of hunger and of any number of other diseases that come linked with malnutrition," says Dr. Iza Ciglenecki, director of emergency programs for MSF.

Even the nation's refugee camps offer little protection. UNICEF has found that over $25 \%$ of refugee children in Chad are acutely malnourished. Some 180000 refugees, two-thirds of them women and children, have fled to Chad in recent years from Sudan's Darfur region.

Repeated poor harvests, drought and pest infestations are behind the crisis, driving up the price of food and forcing families to leave their homes, slaughter or sell livestock and exhaust food stocks earlier than usual. In Niger, the cereal harvest has fallen by $30 \%$, while Chad's last harvest yielded 34\% less grain than the minimum needed to feed the nation.
Ciglenecki says the rise in malnutrition is especially alarming as it coincides with the beginning of the "hunger season," the time between planting and the next harvest when food is scarce even under normal conditions. "That's when the real hunger starts because they have to wait until September or October to replenish their food stocks. It's a vicious cycle because every year there is less food available and people are forced to eat more of their stores that should be saved for the next."

The United Nations' Food and Agriculture Organization warned of the impending food crisis months ago, but delays in funding have resulted in the late purchase and delivery of food to affected areas.

"Everyone knew well in advance that this crisis was coming and much more could have been done in terms of prevention. We missed that opportunity, but there is still time to support treatment of the problem," says Ciglenecki.

National authorities, as well as local and international aid agencies, have 
implemented emergency interventions, such as the creation of inpatient and ambulatory therapeutic feeding centres, but Ciglenecki says many communities have yet to receive assistance. "The local ministries of health are doing their best, but normally they would have very few children hospitalized. Now, they have hundreds of severely ill children being admitted to local hospitals and not enough support to handle them all."

The United Nations' appeal for Niger is currently US\$107 million short of its target. According to Ciglenecki, funds for Chad and other nations are even harder to come by. "The big food crisis in Niger in 2005 is still fresh on everyone's minds, and so it has been easier to raise awareness and assistance for that country. Chad is in the same situation as Niger, but it's not on the international radar in the same way, so there is less assistance and fewer preventative strategies already in place."

It's not known how many deaths have been caused by the food shortages, but Ciglenecki says MSF is preparing to conduct a nutrition and mortality survey in the coming weeks. "For sure there have been increases in the number of deaths we're seeing, but we shouldn't allow the lesson of those deaths to pass. There's still two or three months at least before the next harvest and that's time enough to implement support." - Lauren Vogel, CMAJ

DOI:10.1503/cmaj.109-3315 